\title{
My science, right or wrong!
}

\author{
J. Leo van Hemmen
}

Published online: 30 January 2015

(C) Springer-Verlag Berlin Heidelberg 2015

Slightly before 1820 , in an after-dinner toast, a US Navy officer coined the slogan "My country, right or wrong!" It has been in use ever since-up to the present day. G.K. Chesterton cynically commented, nearly a century later, that "My country, right or wrong" is a thing that no patriot would think of saying. It is like saying, "My mother, drunk or sober." A paraphrase of this rallying cry has insinuated itself into the minds of some scientists: My science, right or wrong! Like its predecessor, this one contains the same malicious idea and appears to be well on its way to being realized. Why is that and what is it good for?

A while ago, say around 2000, spurred by an equally unbounded profit desire of some commercial publishers, the open-access movement was launched. Its key idea sounds very appealing and natural. In general, government, as a representative of the general public, finances scientific research. Thus, it follows, scientific results should be freely accessible to everybody. Let us pause for a minute and consider the implications of this belief. Two words demand our scrutiny here: freely and everybody. What does free mean? Even public libraries are hardly ever free. If they formally are, meaning their services and materials come at no added cost to users, as in the USA, then it is because they are directly supported by tax dollars. Borrowing books from a library or reading the journals it subscribes to requires direct or indirect payment since no library can operate for free and since no publisher

The opinions expressed in this article are those of the author and not necessarily those of the publisher.

J. L. van Hemmen ( $\square)$

Physik Department T35, Technische Universität München, 85747 Garching bei München, Germany

e-mail:1vh@tum.de can provide books or journals free of charge. Someone has to pay.

Furthermore, does everyone really have the knowledge to read and understand articles in a scientific journal? No. To understand a research paper, one needs a solid scientific education, which takes many years to acquire, on average five to six, and to do independent academic research, a doctorate is more or less required. To get to that point, most of us will have spent around 8-10 years at a university. In plain English, the idea of a Public Library of Science, or PLOS for short, is misleading since it cannot, and will not, offer science to the "general" public. And even if it did, it could not do so for free. Someone has to pay for it. The only questions are: Who? And (until recently something no one bothered to ask) in what sense?

To analyze scientific publishing, we ought to clearly identify its main players, viz. authors, referees, readers, and publishers, and in so doing we need to focus on the benefits to all four parties while revealing their activities in producing, reading, and understanding scientific literature.

What is the idea behind open access? A publication ought to be freely accessible to readers, though the author or the author's institution must pay for it. For open-access publishers, this is a wonderful business model since the author is a priori far more interested in getting her or his results published than a prospective reader is in reading it. The author is a client who wants to be served since (s)he pays for it. Accordingly, a journal's requirements for publishing a manuscript can be reduced to the bare minimum of being "methodologically sound," to quote Frontiers, a typical representative [1]. Or, in an apt formulation of the physics Nobel laureate Wolfgang Pauli, it suffices to be "not even wrong." With this standard, the open-access journal PLOS ONE has to date published more than 105,000 papers since 2006, and Frontiers has already surpassed 20,000 since its founding in 
2007. Both journals essentially or exclusively focus on the natural sciences, in particular, biology and neurobiology.

In actual fact, online publishing seems to be so profitable that during the last decade the associated business model of open-access research journals has become very popular: Everything is online, administrative work is done in a virtual office, and after acceptance there is hardly ever any editing of the submitted manuscript. That appears to be the foundation of a highly profitable business, as demonstrated by the many new journals joining the ranks of PLOS and Frontiers. In short, open access stands for big business, big profits, and an even bigger output of scientific papers. In passing, no one has proven yet that for universities, including the authors, the subscription model is inferior to the open-access one. But I would go so far as to take quite the contrary position - that open access is in fact inferior to a combined model of subscription and Open Choice (a hybrid model on which more below) because such a model serves everyone concerned. I say this not because I cannot afford open access, despite being at the most elite German university. I simply believe that it is finally time to leave behind the dogma and face the facts.

Who, then, should read or at least check all this output? Getting things "for free," the reader is simply inundated by mediocre papers and, hence, drowns in all the "knowledge." Slowly but surely, readers come to realize this. On the other hand, authors who cannot pay a minimum of US $\$ 1,350$ and on average US $\$ 3,000$ to get their manuscript published are left out in the cold. Finally, and equally unfortunate, peer review as a means of competent-and necessary!evaluation has fallen off a cliff: A simple calculation [1] based on two reviewers per paper gives a need for 250,000 referees for just the two journals mentioned previously.

There is a counterargument from proponents of open access that may at first seem credible and to settle the matter. The argument goes as follows. Scientists should review papers themselves by reading them. If they do not agree, they can write a reply and publish it. Plausible as this argument might seem, it is not since, in lieu of a few referees, we all then need to carefully check papers first. Disagreement will result in even more of what one might call "scientific obesity." Instead of spending precious time on doing good science, scientists must now waste hours on carefully explaining why something is...wrong. This leads to an even greater flood of papers with no sound scientific basis but must nonetheless be read. What active scientist has time for this nonsense? And it is precisely non-sense in that it makes no sense, except for the open-access journal earning a higher impact factor. As with human obesity, the only solution is to drastically reduce intake. After all, time is one of the most precious commodities. We can spend it only once, and, even more importantly, the amount is quite finite.

With the review of submitted articles being reduced to its bare essentials-or less-the reader gets flooded, as do reviewers, who hence can no longer function properly. Because prices per paper are so high according to academic standards, many scientists cannot afford to publish through open-access channels. And since the client pays for what he or she gets, critical review is, most of the time, though definitely not always, out of the question and the circle is closed. Is it? We are back where we started: Is My science, right or wrong! really the right attitude?

Of course, science does not exist in a vacuum; it is conducted and moves forward through the efforts of a large number of individual scientists, often engaged in heated discussions and an intense exchange of ideas, culminating, ideally, in publication. Some time, say a quarter century, ago there was the furor over so-called publish-or-perish. Have times improved? No, they have apparently gotten worse. Add the ever-present publish-or-perish dogma to the oversized openaccess gateway, and we are all out of luck, despite the shortterm private gain of those who can and do engage in open access. In my opinion, which I believe is extensively supported by the history of science, politicians and scientists play completely different roles, and accordingly there should be a strict segregation between politics and science. This does not mean, though, that science should refrain from making scientific insight available to politicians. Thus, we as scientists need to come to a communis opinio as to how to proceed regarding scientific publishing in a meaningful way (for a suggestion, see below) and explain it to politicians.

There is, in fact, one huge group of journals, such as Biological Cybernetics, that still operate with libraries as a key partner. The latter pay for publishers' services-which is fair because, just as with books, someone must pay-and at the same time the journals maintain high standards of acceptance through conscientious peer review. Moreover, hybrid open-access models, like those offered by most publishers, including Springer's Open Choice, allow those authors with sufficient means to publish their work as open-access papers. Once enough authors get on board with this format, library subscription prices will go down. In my opinion, one should allow authors the freedom of choice to publish traditionally or by open access since, after all, papers originate from authors and not from readers.

Finally, we need to recognize that many standard journal subscription rates are cost-prohibitive for scientists in developing countries. A standard argument is that developing countries are not necessarily poor, which is indeed true for quite a few of them. Thus, an explicit criterion needs to be agreed upon and then applied by, say, UNESCO. Application of a neediness criterion already puts such a heavy political burden on many countries that they will at least pay (reduced) subscription rates. For those who cannot afford a (reduced) subscription rate, UNESCO seems to be the right institution to alleviate their financial problems. In passing, here too we see that subscriptions are an efficient way of addressing the 
issue, all the more so since cheating is practically impossible because UNESCO can pay for subscriptions directly. Where UNESCO in turn gets the money from is a political issue science has no say in.

In summary, with Biological Cybernetics both authors and their science are the focus of attention, not the money someone pays for publishing the manuscripts. Our journal has a long tradition dating back (1961) to such eminent scientists as Barlow, von Békésy, Mittelstaedt, Reichardt, and Wiener; cf. Biol Cybern (2009) 100:3. Hence, evaluation is both crucial and inherently constructive. As a result of this mostly repetitive process, a truly improved manuscript emerges. Of course, it is important to recognize that review is a human affair and, hence, not always flawless and that authors are not always easygoing. Under such a paradigm, journals contribute highquality output to the scientific literature and refrain from content-free flooding. Open Choice allows authors who can afford it to publish open-access papers. Those who can- not afford it are not compelled to bear the financial burden of having their work published. Agencies and universities with sufficient funds are the linchpin in the process; they should understand that open access by itself will not lead to better-quality publications or more important advancements in knowledge than a hybrid system incorporating both open access and subscription. By itself, mere open access is too often a waste of money. Quality and vision are what counts and what Biological Cybernetics stands for.

\section{J. Leo van Hemmen \\ Editor-in-Chief, Biological Cybernetics}

\section{Reference}

1. Arns M (2014) Open access is tiring out peer reviewers. Nature 515:467. For all data mentioned in the present editorial the reader is referred to Wikipedia, which also offers a detailed referencing 